\title{
Acoustic Emission of Metallic Specimen with Surface Defect During Fatigue Crack Growth
}

\author{
X. Yao ${ }^{1, a^{\star}}$, B.S. Vien ${ }^{1, b}$, N. Rajic ${ }^{2, c}$, L.R.F. Rose ${ }^{2, d}$, C.H.J. Davies ${ }^{1, e}$, \\ W.K. Chiu ${ }^{1, f}$ \\ ${ }^{1}$ Department of Mechanical and Aerospace Engineering, Monash University, Wellington Rd, \\ Clayton, VIC 3800, Australia \\ ${ }^{2}$ Defence Science and Technology Group, 506 Lorimer Street, Fisherman's Bend, VIC 3207, \\ Australia \\ aXinyue.Yao@monash.edu, b ben.vien@monash.edu, CNik.Rajic@dst.defence.gov.au, \\ dFrancis.Rose@dst.defence.gov.au, e'Chris.Davies@monash.edu, \\ fWing.Kong.Chiu@monash.edu
}

Keywords: Acoustic Emission, Fatigue Crack, Wave Propagation, Lamb Wave

\begin{abstract}
Acoustic emission is defined as the phenomena whereby transient elastic waves are generated by the rapid release of localized sources within a material. During fatigue crack growth, the formation of new crack surfaces is associated with a sudden release of energy, which constitutes acoustic sources for acoustic emission. This paper investigates the acoustic emission signature arising from fatigue test of a metallic specimen under tensile fatigue test. In this experimental study, dog-bone aluminium alloy specimen with a surface defect was fatigued to failure. It is found that the acoustic emission characteristics are different during the propagation of surface crack, because the source is changing. The results provide a useful guide in identifying source origin based on the characteristics of the acoustic emission waveform.
\end{abstract}

\section{Introduction}

Aluminium alloys have been used in aerospace since the 1920s. The strength, hardness, and corrosion resistance of aluminium alloys increased dramatically as the aerospace industry developed. Although composite materials have been employed over recent decades, aluminium alloys are still widely used and contribute to over $50 \%$ of the total weight of an aircraft [1]. It is known that aluminium alloys are susceptible to fatigue damage and there has been a significant amount of research towards the development of structural health monitoring methodologies to detect and monitor the onset of fatigue damage and the eventual fatigue crack growth [2-5].

The advanced non-destructive testing methods for metal material include near-infrared cameras (NIR), laser ultrasonics, and X-ray computed tomography [6-8]. Although these methods can reveal the defect by image clearly, there is still a need for a non-destructive method which has the potential to reveal the fatigue failure stages. In-situ acoustic emission (AE) testing is a widely used non-destructive testing approach for locating and classifying defects in rock, concrete, composite, and metal [9-14]. It is a real-time monitoring method of efficiency and high-performance and is used in monitoring equipment under active stress or machining processes [15-17]. According to previous research, AE has the potential to predict the stages of crack propagation during operation $[4,5,18-20]$. Thus, the AE method has a real and significant application in real-time structural health monitoring. When using AE to monitor fatigue crack growth, the possible AE sources include the formation of a new fracture surface and the rubbing or clapping of interface crack surface $[21,22]$. 
The transient wave in an AE signal is called hit, and it is usually understood as "an isolated and separated" waveform [23]. Previous studies on AE were focusing on hit-related information during fatigue tests, including the relationship between count rate and material rolling direction [24], and the relationship between count number on fatigue cycle and crack propagation rate [5]. Nevertheless, recent works on AE have focused on waveform pattern analysis and highlighted the importance of studying $\mathrm{AE}$ waveform $[25,26]$, because it could provide more information than only analysing hit-related characteristics. It is found that AE signals of aluminium alloys 7075-T6 have peak frequencies around $100 \mathrm{kHz}, 260 \mathrm{kHz}$ and $600 \mathrm{kHz}$ [20]. Other research also found different frequency peaks of low carbon steel [26] or aluminium alloy 2024 T3 [27]. Studies on AE waveforms are often challenging because the amplitude and frequency of AE waveforms can vary significantly. Sause and Hamstad stated that the frequency characteristics could be relatively irrelevant in some cases, because the AE sensors were of variety and could affect collected frequency [28]. For example, some sensors may provide more information on frequency than others [25]. Therefore, it is important to have a more comprehensive rule to cluster AE hits, so wave modes identification becomes very important.

The elastic waves excited by AE signal in a thin plate-like structure are Lamb waves, which have symmetric modes and asymmetric modes. The most frequently discussed modes include zero-order asymmetric mode (A0), zero-order symmetric mode (S0), and first-order asymmetric mode (A1). The group velocities for distinct wave modes vary with frequency due to its dispersive nature and can be used in identifying wave modes. The most frequently used AE sensors are piezoelectric wafer active sensors and typically are threshold-based sensors that only record AE signals which exceed the set threshold level to discard possible background noise [26]. Unlike the active wave sensing approach, where guided waves are excited by a transmitter sensor [29], AE is a passive monitoring approach that listens for waves generated by rapid energy released from the structures themselves. Making use of this phenomenon, by aligning the theoretical dispersion curve with the wavelet transform, certain wave modes can be identified [30]. The influence of the source location in the thickness direction to AE wave modes has been investigated by some researchers for plate-like structure. Hamstad [31] showed that the PLB source location in the thickness direction of plate affects the generated wave modes: the in-plane PLB signal near top of the edge has only A0 mode, and that near mid-plane has both A0 and S0 modes. Yu et al. [32] differentiated the delaminations and transverse cracks of composites by A0/S0 mode amplitude ratio. They also conducted an FEA of a thin plate with monopole input source, and results indicated that as the source location moved closer to the surface from the mid-plane, the ratio of $\mathrm{A} 0$ and $\mathrm{A} 1$ modes increased, and that of $\mathrm{S} 0$ decreased. As a result, wave mode decomposition results have the ability to indicate source locations and source origins.

This paper presents a set of findings in using AE to monitor the fatigue crack development in an aluminium plate-like specimen. In describing the formation of new fatigue crack surface as a source of acoustic emission, the paper reports on the differences in the stress wave generated by propagating radial crack front.

\section{Methods}

Experimental method. The samples tested were dog-bone specimens with gauge width 40mm of and thickness of 3mm (Fig. 1a) made from aluminium alloy 6060 (A16060) and its material properties are shown in Table 1 . It has a thin surface defect $(2 \mathrm{~mm}$ length, around $0.5 \mathrm{~mm}$ width, and $0.5 \mathrm{~mm}$ depth) in the centre of the specimen (shown in Fig. 1b). The defect was first drilled with a $0.5 \mathrm{~mm}$ diameter drill for $0.5 \mathrm{~mm}$ depth in the middle, and then a $2 \mathrm{~mm}$ length $0.5 \mathrm{~mm}$ 
depth line crack was engraved over it. The artificial defect was intended to cause stress concentration and initialise the fatigue fracture.

Table 1: Al6060 specimen with through-thickness defect material properties.

\begin{tabular}{ll}
\hline Young's Modulus & $\mathbf{6 8 ~ G P a}$ \\
\hline Poisson's Ratio & 0.33 \\
\hline Density & $2.7 \mathrm{~g} / \mathrm{cm}^{3}$ \\
\hline Tested yield stress & $100 \mathrm{MPa}$ \\
\hline Tested ultimate stress & $150 \mathrm{MPa}$
\end{tabular}

Initial defect location

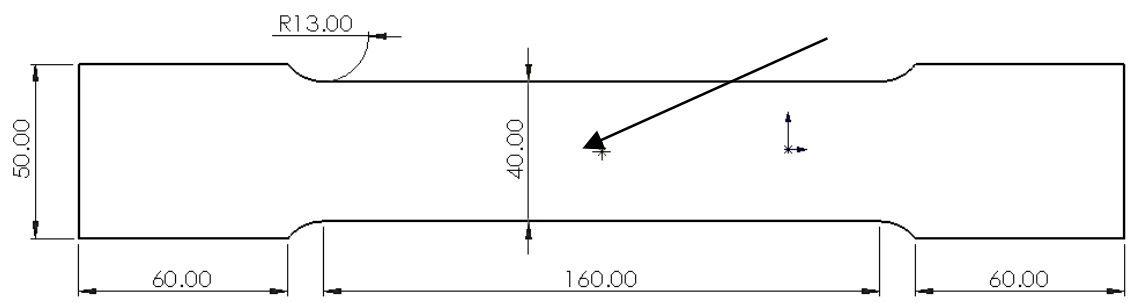

(a)

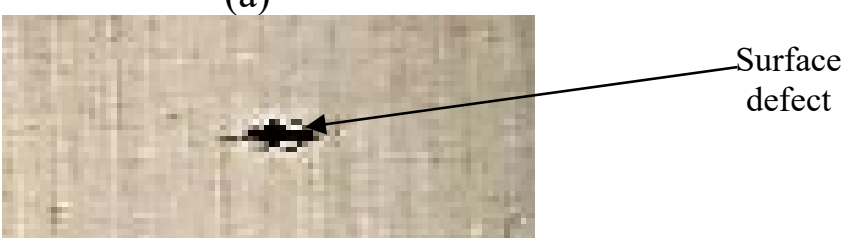

(b)

Figure 1. (a) Dimension of samples. (b) Surface defect.

The specimens were fatigue tested using MTS machine Model 647. The specimens were tested cyclically from $43 \mathrm{MPa}$ to $74 \mathrm{MPa}$ until failure with $\mathrm{R}$ ratio 0.58 . The fatigue cycling was paused when significant hits were recorded so that the fatigue fracture can be observed, and the $\mathrm{AE}$ waveform and the corresponding fatigue cycle were analysed afterwards.

The Physical Acoustic Corporation acoustic emission sensors and recording system were used in the experiments. Two wideband PKWDI sensors detected from $200 \mathrm{kHz}$ to $850 \mathrm{kHz}$ were used, and they were connected to a two-channel Micro Structural Health Monitoring, with a $26 \mathrm{~dB}$ build-in pre-amplifier. The centres of the sensors are both $20 \mathrm{~mm}$ away from the defect.

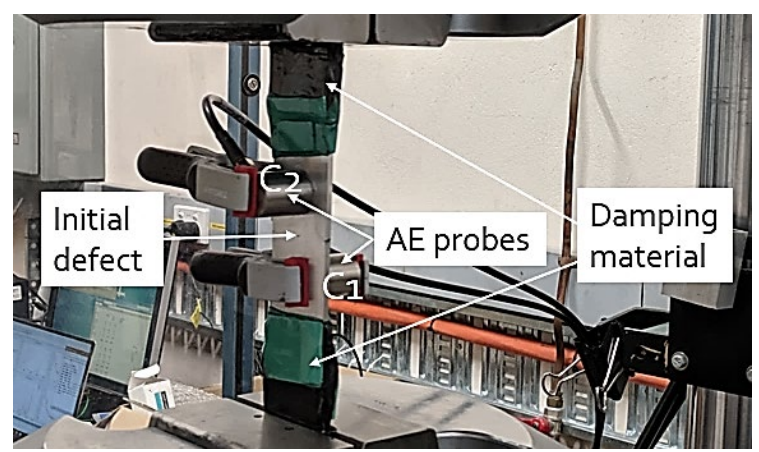

(a)

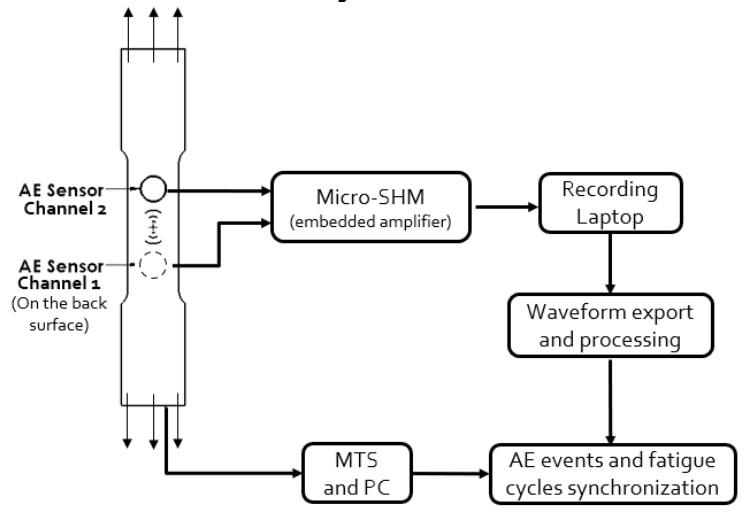

(b)

Figure 2. (a) Photo of the experimental set-up. (b) Illustration of equipment set-up. 
The threshold setting of the acoustic emission equipment was done using a widely accepted artificial simulating source for acoustic emission, which was Hsu-Nielsen source, or also called pencil lead break (PLB) source [33]. In order to mitigate the test specimen from the noise generated by the MTS machine, the regions of the test specimen in the vicinity of the grips were treated with a damping layer (MegaSorber type DIS8) [34]. The damping sheets were cut into small pieces and carefully attached on both ends of the specimen, and the threshold setting was adjusted accordingly. Because the specimen was not symmetric, Channel 1 (C1) was placed on the non-defect side, and Channel 2 (C2) was placed on the initial surface defect side (see Fig. 2a).

\section{Results and discussions}

Hit-related Feature Discussion. The hits were applied a high pass $60 \mathrm{kHz}$ filter first to eliminate the low frequency vibration noise. The valid AE source from the defect should be from the area around the initial crack, which is in the middle of two sensors. Thus, the AE events of two channels were synchronized using the waveform event synchronization function in the AE-win software, where the hits were synchronized according to the time of collection. The event definition time was set as $50 \mu$ s to allow some error. Thus, the AE hits collected by only one of the sensors was discarded.

The fatigue crack fracture surface of the specimen is shown in Fig. 3. The crack propagated radially from the initial surface defect until the other surface and then progressed to the edge of the specimen.

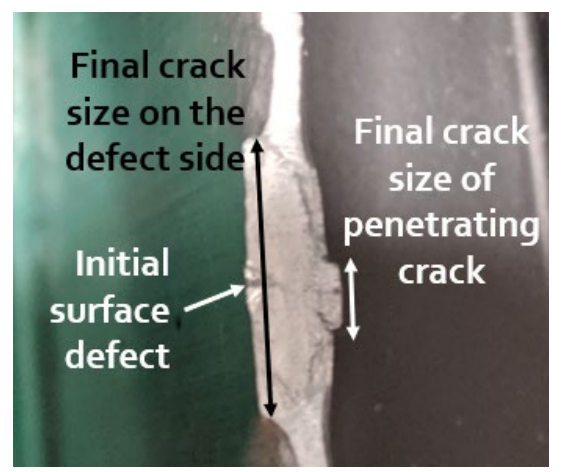

Figure 3. Final crack surface after fatigue test till to failure.

In Fig. 4a, the hit number increases slightly at the beginning of the test when the specimen was still settling, and the number almost keeps identical until a rapid increase in the lasts 10,000 cycles before failure. The majority of the events happened during the last 10,000 cycles of total 191341 cycles. In Fig. 4b, there are large-amplitude hits at the end of the test due to the specimen broke into two pieces, while the amplitudes of other hits are very consistently between 0 and 0.011 volts. It can be seen that the amplitude between hit 1000 to hit 3000 has a relatively constant amplitude between 0.007 volts and 0.01 volts, while from hit 4000 to hit 5700 , the amplitudes are alternating between two values that have a relatively big difference: around 0.003 volts and around 0.007 volts. This will be discussed more in the next section with the time difference between two hits together. 


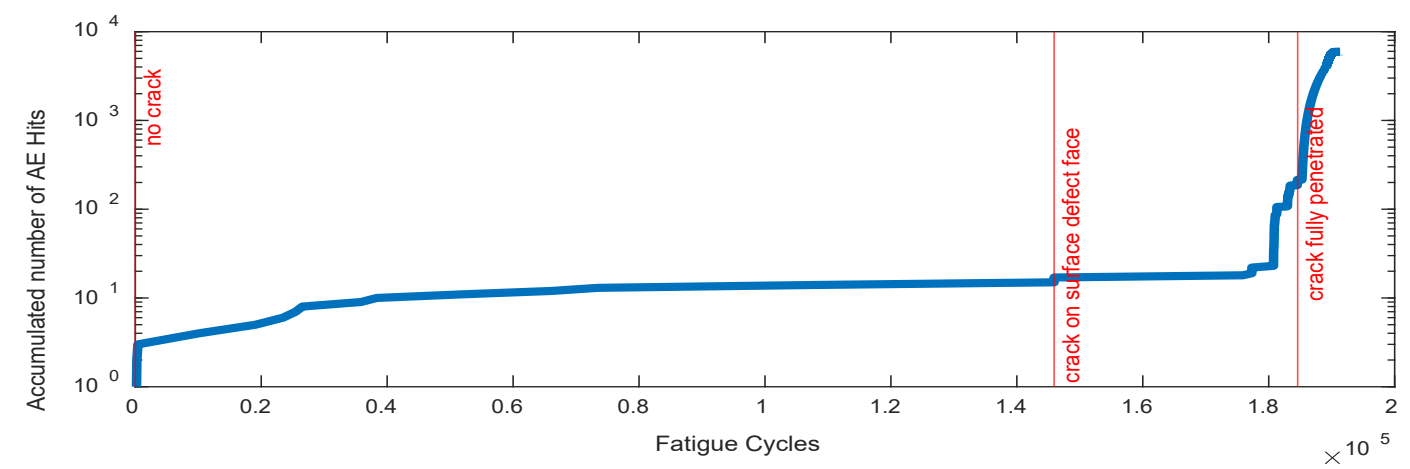

(a)

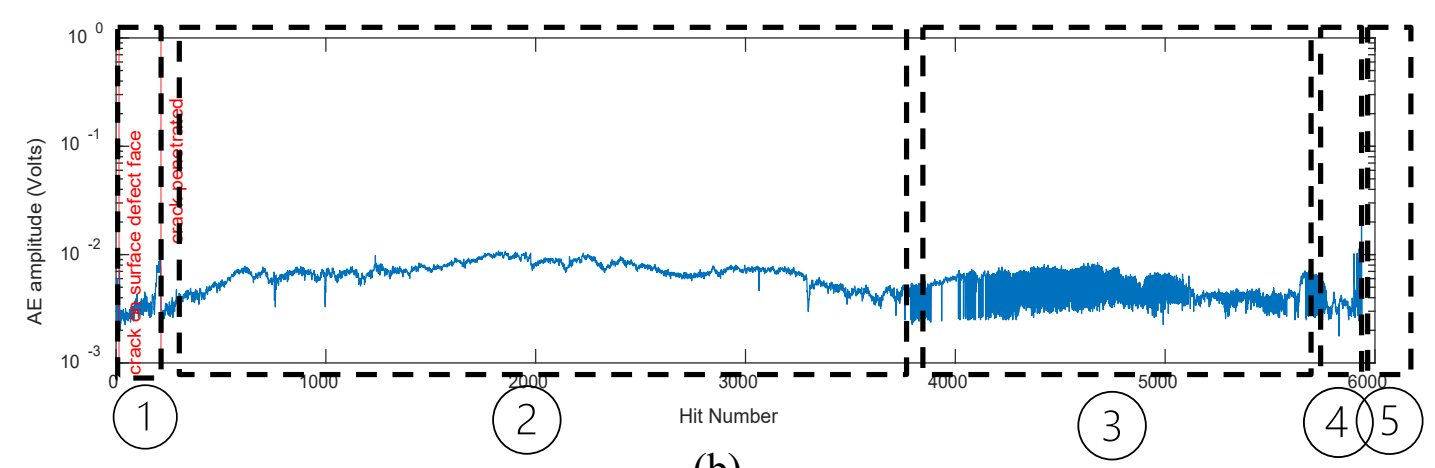

(b)

Figure 4. (a) Number of AE hits vs fatigue cycles. (b) Amplitude of each hit during test.

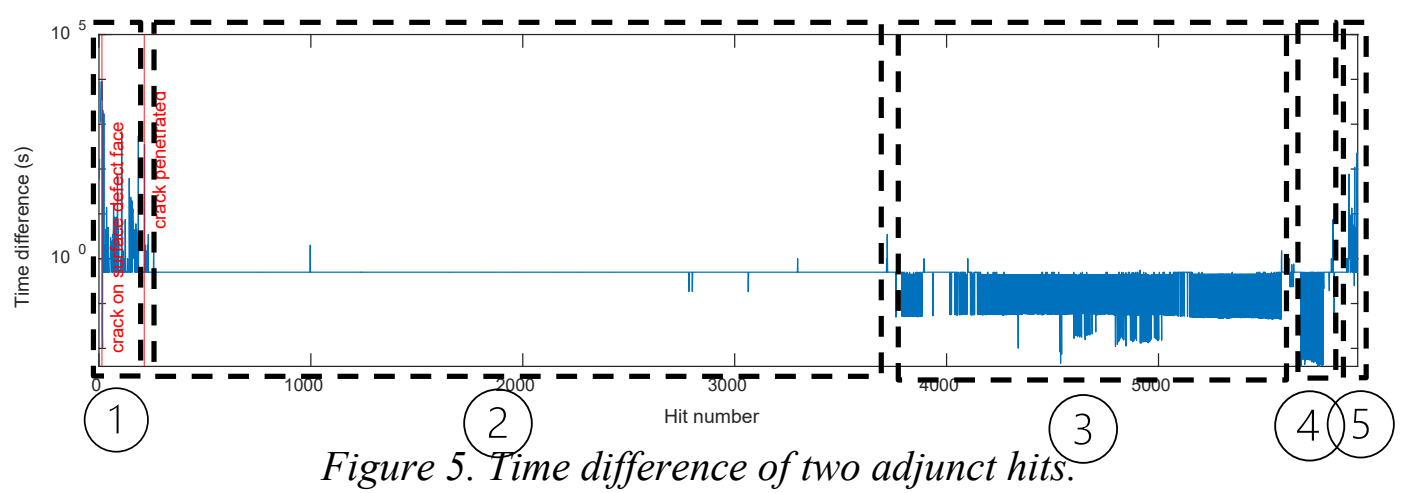

Source and Waveform Discussion. The hits were divided into 5 periods according to the time difference between the current signal and its adjacent previous hit, shown in Fig. 5. In addition, the Fast Fourier Transformation (FFT) of each hit from both channels are illustrated in Fig. 6. The description details of each period are written in Fig. 7 column 1. In period 1, the time difference shown in Fig. 5 is random. when there was crack seen on only one side of the specimen, the FFT diagram of $\mathrm{C} 1$ and $\mathrm{C} 2$ shows $260 \mathrm{kHz}$ are dominant. In period 2, the time differences are consistently $0.5 \mathrm{~s}$. When the fatigue crack penetrated through the surface to the opposite side of the initial defect, the dominant frequency of $260 \mathrm{kHz}$ and around $600 \mathrm{kHz}$ is getting more obvious. In period 3, the time difference in Fig. 5 alternates between 0.05 and $0.44 \mathrm{~s}$, and that of period 4 alternates between 0.005 and $0.5 \mathrm{~s}$. In period 5 , the time difference becomes random again as period 1. In addition, the time takes for another hit to arrive of period 1 and 5 are obviously longer than period 2 to 4 . It is also worth noting that from period 2 to 4 when the crack is propagating, the time difference is regular: for period 2, it is one hit per cycle 
because the load frequency is $2 \mathrm{~Hz}$; for period 3 and 4 , there are two hits per loading cycle. Relating to the amplitude diagram, in period 2, when the time difference is consistent, the amplitude is relatively consistent as well. In period 3 and 4, when the time difference is close to 0 seconds, the amplitude is around 0.003 volts; when the time difference is around 0.5 seconds, the amplitude is about 0.007 volts.

In Bhuiyan and Giurgiutiu' study [27], they clustered the AE hits according to the frequency characteristics, and it was found that for some clustered groups, the frequency characteristics of hits collected, amplitudes of hits and the fatigue load level that the hit happens are almost identical for each hit. The results in this paper is similar to their findings about the consistency between hit signatures and fatigue cycles. However, they did not present the hit over the whole fatigue process. In this paper, it is found that this consistency is true during the whole fatigue test after crack arise. In addition, their specimen is a symmetric specimen with a through-hole, while this paper shows that the asymmetric specimen with surface defect also have similar results. Unfortunately, this paper did not synchronise hit with load level as accurate as their work.

The regular hit arising time in Fig. 5 indicates that the possible source origin could be from the opening and closing of the crack, or crack extension itself. In [35], It is found that the hits from crack extensions or inclusion fractures happened when maximum load is applied, and only take up to $10 \%$ of the total AE activity. The load is not synchronised in this paper, so for future work, synchronisation with the fatigue load would be considered to identify hits from crack extensions.



Refer to Fig. 7, most of the values of the time difference between two paired hits are within 8 $\mu \mathrm{s}$, so this means that the source location is within the middle area of two sensors. In period 2, generally, the time arriving difference is very small and relatively consistent. From this phenomenon, it can be speculated that these hits are from one same source in the middle, and because it is happening once per fatigue cycle after crack just penetrated, it is highly likely to be caused by closure/friction of the crack surface. In period 3 and 4, the source in period 2 is still there, but there exists one more source that is happening very close to the previous one ( $\Delta \mathrm{t}$ is $0.05 \mathrm{~s}$ or $0.005 \mathrm{~s}$ ). This new source is highly likely from the separation of stuck crack faces [35]. The reasons why this source did not arise in period 2 is that, in period 2, the defect has just penetrated and has only the crack labelled 1 (see Fig. 8), while in the later fatigue stage, crack labelled 2 arose and it is more likely to cause AE activity when separating because of the saw shape [27]. 


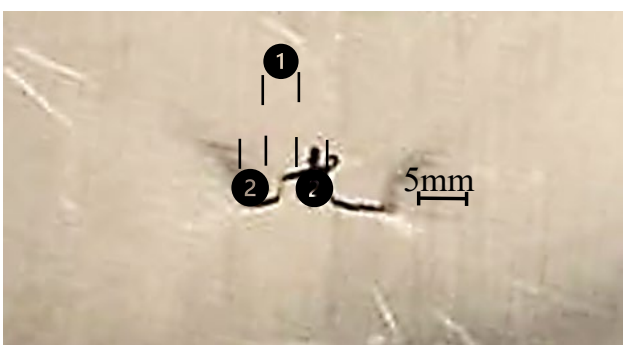

Figure 8. Crack profile on the back surface before failure.

To study the dominant frequency characteristics in detail of each period, seven example waveforms were shown in each stage to illustrate the evolution of dominant frequency for both channels. Fig. 9 shows the wavelet transform of the AE events during the surface crack propagation. The first waveform was collected when there existed crack only on one surface, the amplitude of that is small compared to the later ones. The $270 \mathrm{kHz}$ frequency is more obvious. For waveform from period 2, period 3 when $\Delta \mathrm{t}$ is $0.05 \mathrm{~s}$, and period 4 when $\Delta \mathrm{t}$ is $0.005 \mathrm{~s}$, a higher frequency around $600 \mathrm{kHz}$ arises for both channels. For period 3 when $\Delta \mathrm{t}$ is $0.44 \mathrm{~s}$ and period 4 when $\Delta \mathrm{t}$ is $0.5 \mathrm{~s}$, the lower frequency still dominates. Possible reasons for this frequency shifting could be of different source origin.

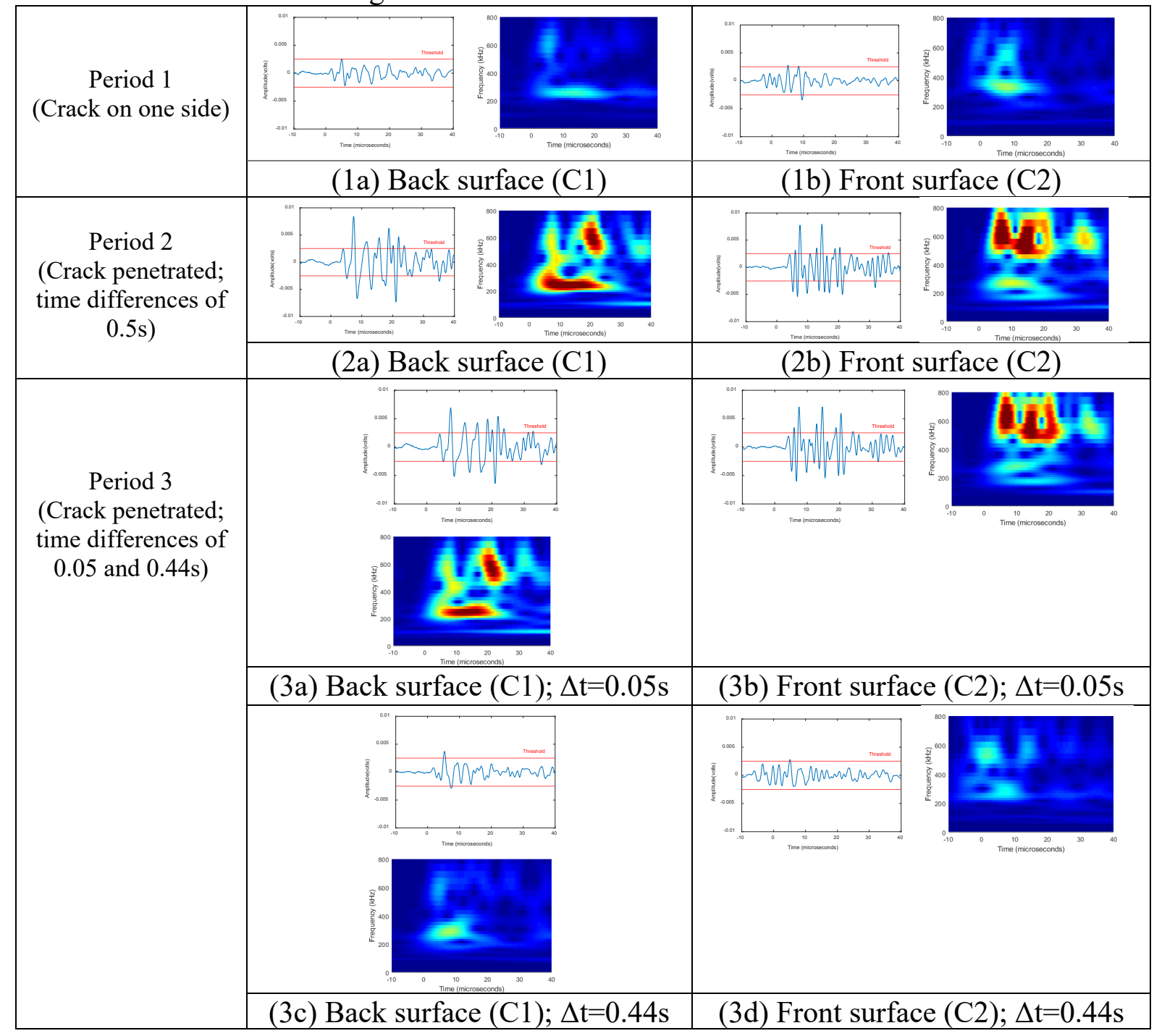




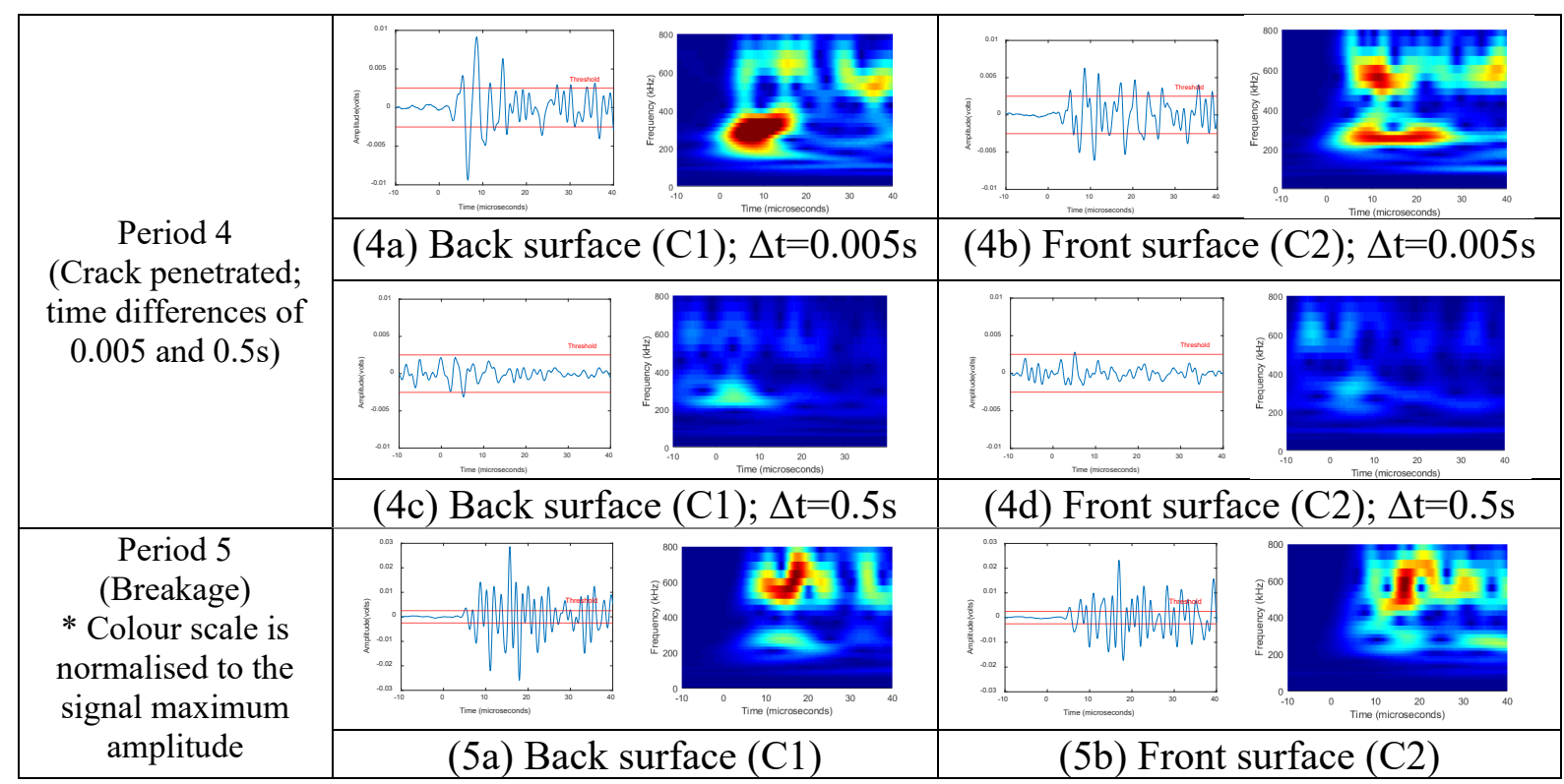

Figure 9.7 chosen waveforms and corresponding wavelet transform.

Because the actual source arising time is unknown in this situation, and the source is only 20 $\mathrm{mm}$ from the sensor, it can be inaccurate to align the wavelet transform with the dispersion curve just by observing. Whilst similar observations can be qualitatively made, a better description of the modal content of the acoustic emission is required in order to delineate the contribution from S0, A0 and A1 modes during the period of fatigue crack propagation. Knowledge of the measured dispersion curve is necessary to delineate the contributions from these wave modes and to derive quantitative ratios of the guided-wave modes to describe the fatigue crack propagation. This highlights the limitation of the current measurement technique and underscores the potential of using a multi-element sensing arrangement described by Rajic et al [36].

\section{Conclusion}

This paper has reported the acoustic signature of an artificial surface defect on dog-bone shaped Al6060 specimens under tensile fatigue test. It is found that most of AE events were collected in very late fatigue stage. Closure/friction and separation of crack surface contribute to most of the $\mathrm{AE}$ activities for the surface defect specimen. In addition, different source origins have a different ratio of dominant frequencies. This phenomenon indicates that, by monitoring AE waveforms, it is possible to predict the source of AE. Future work will account for wave modes decomposition on the fatigue crack propagation process and its associated AE characteristics.

\section{References}

[1] A. P. Mouritz, Introduction to aerospace materials. Elsevier, 2012. https://doi.org/10.1533/9780857095152

[2] W. H. Ong and W. K. Chiu, "Designing for Lamb Wave Based In Situ Structural Health Monitoring," Key Engineering Materials, vol. 558, pp. 411-423, 2013. https://doi.org/10.4028/www.scientific.net/KEM.558.411

[3] J. Jones, "Enhancing the Accuracy of Advanced High Temperature Mechanical Testing through Thermography," Applied Sciences, vol. 8, no. 380, p. 19, 2018. https://doi.org/10.3390/app8030380 [4] C. K. Lee, P. D. Wilcox, B. W. Drinkwater, J. Scholey, M. Wisnom, and M. Friswell, "Acoustic emission during fatigue crack growth in aluminium plates," Proceedings of the ECNDT, Berlin, Germany, pp. 25-29, 2006. https://doi.org/10.4028/0-87849-420-0.23 
[5] T. M. Roberts and M. Talebzadeh, "Acoustic emission monitoring of fatigue crack propagation," Journal of constructional steel research, vol. 59, pp. 659-712, 2003. https://doi.org/10.1016/S0143974X(02)00064-0

[6] H. Helvajian et al., "Evaluation of laser ultrasonic testing for inspection of metal additive manufacturing," presented at the Laser 3D Manufacturing II, 2015.

[7] M. Mazurek and R. Austin, "Nondestructive Inspection of Additive Manufactured Parts in the Aerospace Industry," vol. 3,

[8] A. Thompson, I. Maskery, and R. K. Leach, "X-ray computed tomography for additive manufacturing: a review," Measurement Science and Technology, vol. 27, no. 7, 2016. https://doi.org/10.1088/0957-0233/27/7/072001

[9] M. J. Eaton, R. Pullin, and K. M. Holford, "Acoustic emission source location in composite materials using Delta T Mapping," Composites Part A: Applied Science and Manufacturing, vol. 43, no. 6, pp. 856863, 2012. https://doi.org/10.1016/j.compositesa.2012.01.023

[10] J. Fortin, S. Stanchits, G. Dresen, and Y. Gueguen, "Acoustic Emissions Monitoring during Inelastic Deformation of Porous Sandstone: Comparison of Three Modes of Deformation," Pure and Applied Geophysics, vol. 166, no. 5-7, pp. 823-841, 2009. https://doi.org/10.1007/s00024-009-0479-0

[11] S. K. Al-Jumaili, M. J. Eaton, K. M. Holford, M. R. Pearson, D. Crivelli, and R. Pullin, "Characterisation of fatigue damage in composites using an Acoustic Emission Parameter Correction Technique," Composites Part B: Engineering, vol. 151, pp. 237-244, 2018. https://doi.org/10.1016/j.compositesb.2018.06.020

[12] W. Zhou, W.-z. Zhao, Y.-n. Zhang, and Z.-j. Ding, "Cluster analysis of acoustic emission signals and deformation measurement for delaminated glass fiber epoxy composites," Composite Structures, vol. 195, pp. 349-358, 2018. https://doi.org/10.1016/j.compstruct.2018.04.081

[13] J. P. McCrory et al., "Damage classification in carbon fibre composites using acoustic emission: A comparison of three techniques," Composites Part B: Engineering, vol. 68, pp. 424-430, 2015. https://doi.org/10.1016/j.compositesb.2014.08.046

[14] D. G. Aggelis, E. Z. Kordatos, and T. E. Matikas, "Acoustic emission for fatigue damage characterization in metal plates," Mechanics Research Communications, vol. 38, no. 2, pp. 106-110, 2011. https://doi.org/10.1016/j.mechrescom.2011.01.011

[15] J. G. e. E. Govekar, I. Grabec, "Analysis of acoustic emission signals and monitoring of machining process," Ultrasonics, vol. 38, pp. 598-603, 2000. https://doi.org/10.1016/S0041-624X(99)00126-2

[16] I. Inasaki, "Application of acoustic emission sensor," Ultrasonics, vol. 36, pp. 273-281, 1998. https://doi.org/10.1016/S0041-624X(97)00052-8

[17] H. A. Kishawy, H. Hegab, U. Umer, and A. Mohany, "Application of acoustic emissions in machining processes: analysis and critical review," The International Journal of Advanced Manufacturing Technology, vol. 98, no. 5-8, pp. 1391-1407, 2018. https://doi.org/10.1007/s00170-018-2341-y

[18] S. M. C. C. M. SCALA, "Acoustic Emission during Fatigue Crack Propagation in the Aluminium Alloys 2024 and 2124," Materials Science and Engineering, vol. 61, pp. 211-218, 1983. https://doi.org/10.1016/0025-5416(83)90102-7

[19] T. Lindley, I. Palmer, and C. Richards, "Acoustic emission monitoring of fatigue crack growth," Materials Science and Engineering, vol. 32, no. 1, pp. 1-15, 1978. https://doi.org/10.1016/00255416(78)90206-9

[20] H. Chang, E. Han, J. Wang, and W. Ke, "Acoustic emission study of corrosion fatigue crack propagation mechanism for LY12CZ and 7075-T6 aluminum alloys," Journal of materials science, vol. 40, no. 21, pp. 5669-5674, 2005. https://doi.org/10.1007/s10853-005-1300-9 
[21] S. M. Cousland and C. Scala, "Acoustic emission during the plastic deformation of aluminium alloys 2024 and 2124," Materials Science and Engineering, vol. 57, no. 1, pp. 23-29, 1983. https://doi.org/10.1016/0025-5416(83)90023-X

[22] R. Joseph, M. Y. Bhuiyan, and V. Giurgiutiu, "Acoustic emission from vibration of cracked sheetmetal samples," Engineering Fracture Mechanics, vol. 217, 2019. https://doi.org/10.1016/j.engfracmech.2019.106544

[23] R. Unnorsson, "Hit Detection and Determination in AE Bursts," in Acoustic Emission - Research and Applications, 2013, ch. Chapter 1. https://doi.org/10.5772/54754

[24] S. M. K. Cousland and C. Scala, "Acoustic emission from the aluminium alloy 6061-T651," Journal of materials science letters, vol. 3, no. 3, pp. 268-270, 1984. https://doi.org/10.1007/BF00726813

[25] M. Y. Bhuiyan, B. Lin, and V. Giurgiutiu, "Acoustic emission sensor effect and waveform evolution during fatigue crack growth in thin metallic plate," Journal of Intelligent Material Systems and Structures, vol. 29, no. 7, pp. 1275-1284, 2017. https://doi.org/10.1177/1045389X17730930

[26] H. Bi, Z. Li, D. Hu, I. Toku-Gyamerah, and Y. Cheng, "Cluster analysis of acoustic emission signals in pitting corrosion of low carbon steel," Materialwissenschaft und Werkstofftechnik, vol. 46, no. 7, pp. 736-746, 2015. https://doi.org/10.1002/mawe.201500347

[27] M. Y. Bhuiyan and V. Giurgiutiu, "The signatures of acoustic emission waveforms from fatigue crack advancing in thin metallic plates," Smart Materials and Structures, vol. 27, no. 1, p. 015019, 2018. https://doi.org/10.1088/1361-665X/aa9bc2

[28] M. Sause and M. Hamstad, "7.14 Acoustic Emission Analysis," in Comprehensive Composite Materials II, 2018, pp. 291-326. https://doi.org/10.1016/B978-0-12-803581-8.10036-0

[29] W. J. Staszewski, B. C. Lee, L. Mallet, and F. Scarpa, "Structural health monitoring using scanning laser vibrometry: I. Lamb wave sensing," Smart Materials and Structures, vol. 13, no. 2, pp. 251-260, 2004. https://doi.org/10.1088/0964-1726/13/2/002

[30] M. Hamstad, A. O‘GALLAGHER, and J. Gary, "A wavelet transform applied to acoustic emission," J. Acoust. Emiss, vol. 20, pp. 39-61, 2002.

[31] M. Hamstad, "Acoustic emission signals generated by monopole (pencil lead break) versus dipole sources: finite element modeling and experiments," Journal of acoustic emission, vol. 25, pp. 92-106, 2007.

[32] F. Yu, Q. Wu, Y. Okabe, S. Kobayashi, and K. Saito, "The identification of damage types in carbon fiber-reinforced plastic cross-ply laminates using a novel fiber-optic acoustic emission sensor," Structural Health Monitoring: An International Journal, vol. 15, no. 1, pp. 93-103, 2016. https://doi.org/10.1177/1475921715624503

[33] N. Hsu and B. FR, "Characterization and calibration of acoustic emission sensors," 1981.

[34] "Vibration Isolation: Megasorber DIS8 Self-Adhesive Vibration Isolation and Damping Sheet," ed: Megasorber Pty Ltd, 2018.

[35] K. Ono, "Acoustic emission," in Springer Handbook of Acoustics: Springer, 2014, pp. 1209-1229. https://doi.org/10.1007/978-1-4939-0755-7_30

[36] N. Rajic, C. Rosalie, S. van der Velden, L. F. Rose, J. Smithard, and W. K. Chiu, "A novel high density piezoelectric sensing capability for in situ modal decomposition of acoustic emissions," in Proceedings of the 9th European Workshop on Structural Health Monitoring July, 2018, pp. 10-13, 